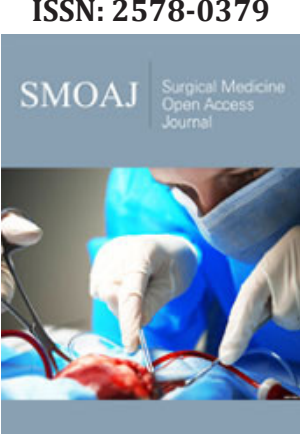

*Corresponding author: Majid MM, Mustansiriyah University/College of Science, Baghdad, Iraq

Submission: 眥 February 15, 2021

Published: 湴April 01, 2021

Volume 4 - Issue 3

How to cite this article: Majid MM. An Affordable Way to Treat Frozen Shoulder. Surg Med Open Acc J. 4(3). SMOAJ.000586. 2021. DOI: 10.31031/SMOAJ.2021.04.000586

Copyright@ Majid MM, This article is distributed under the terms of the Creative Commons Attribution 4.0 International License, which permits unrestricted use and redistribution provided that the original author and source are credited.

\section{An Affordable Way to Treat Frozen Shoulder}

\author{
Majid MM*
}

Mustansiriyah University/College of Science, Baghdad, Iraq

\section{Opinion}

Frozen shoulder, or adhesive capsulitis, a condition characterized by pain and stiffness in the shoulder. And over time, moving the shoulder becomes difficult and extremely painful. It commonly affects people between 40 and 60 of age and occurs in women more often than men. People with diabetes are more likely to develop frozen shoulder. Physical therapy, with a focus on shoulder flexibility, is the primary treatment recommendation for frozen shoulder. In an attempt to find an accessible and effective way to treat the frozen shoulder, a sample of 13 volunteers with the frozen shoulder was selected and asked to follow the following method, which involves exposing the affected shoulder to a stream of hot water (Maximum tolerable water temperature $\approx 40{ }^{\circ} \mathrm{C}$ ) for a continuous 5-7 minutes, with a rotating movement of the shoulder. Eight of the thirteen patients had symptoms that disappeared permanently and no longer felt pain or stiffness, and their normal ability to move the shoulder joint returned to its previous state before the disease. In the other five patients, the symptoms improved significantly, with some symptoms remaining and some limited movement. This may be related to not reaching the required time and temperature. Which may require repeated trying one or more times to reach the desired recovery.
For possible submissions Click below:

\section{Submit Article}

